\title{
Adsorption of Eu(III) on oMWCNTs: Effects of pH, Ionic Strength, Solid-Liquid Ratio and Water-Soluble Fullerene
}

\author{
P. Liu, ${ }^{1}$ J. Wang, ${ }^{1}$ W. Qi, ${ }^{1} \mathrm{Zh} . ~ L i,^{2}{ }^{J J} . \mathrm{Bi}^{1}{ }^{1}$ and WS. Wu ${ }^{1,3}$ \\ ${ }^{1}$ Radiochemistry Laboratory, School of Nuclear Science and Technology, Lanzhou University, Lanzhou, Gansu 730000, China \\ ${ }^{2}$ Institute of Modern Physics, Chinese Academy of Sciences, Lanzhou, Gansu 730000, China \\ ${ }^{3}$ State Key Laboratory of Applied Organic Chemistry, Lanzhou University, Lanzhou, Gansu 73000, China
}

Correspondence should be addressed to Wangsuo WU; wuws@lzu.edu.cn

Received 30 May 2013; Accepted 7 July 2013

Academic Editor: Myoung-Woon Moon

Copyright (C) 2013 Peng LIU et al. This is an open access article distributed under the Creative Commons Attribution License, which permits unrestricted use, distribution, and reproduction in any medium, provided the original work is properly cited.

\begin{abstract}
The influences of $\mathrm{pH}$, ionic strength, solid-liquid ratio, $\mathrm{C}_{60}\left(\mathrm{C}(\mathrm{COOH})_{2}\right)_{n}$, and $\mathrm{C}_{60}(\mathrm{OH})_{n}$ on Eu(III) adsorption onto the oxidation multiwalled carbon nanotubes (oMWCNTs) were studied by using batch technique. The dynamic process showed that the adsorption of $\mathrm{Eu}(\mathrm{III})$ onto oMWCNTs could be in equilibrium for about $17 \mathrm{~h}$ and matched the quasi-second-order kinetics model. The sorption process was influenced strongly by $\mathrm{pH}$ changes and ionic strength. In the $\mathrm{pH}$ range of 1.0 to 4.0 , the adsorption ratio increased with the increasing of $\mathrm{pH}$ values, then the adsorption of $\mathrm{Eu}(\mathrm{III})$ was almost saturated in the $\mathrm{pH}$ range of 4.0 to 10.0 , and the adsorption ratio reached about $90 \%$. The adsorption ratio decreased with the increasing of ionic strength. $\mathrm{C}_{60}\left(\mathrm{C}(\mathrm{COOH})_{2}\right)_{2}$ could promote the adsorption process obviously, but $\mathrm{C}_{60}(\mathrm{OH})_{n}$ competed with $\mathrm{Eu}(\mathrm{III})$ for the adsorption sites, thus leading to the reducing of $\mathrm{Eu}(\mathrm{III})$ adsorption onto oMWCNTs. In the presence of $\mathrm{C}_{60}\left(\mathrm{C}(\mathrm{COOH})_{2}\right)_{n}$ or $\mathrm{C}_{60}(\mathrm{OH})_{n}$, the adsorption of Eu(III) onto oMWCNTs could be affected obviously by solid-liquid ratio and the initial concentration of $\mathrm{Eu}(\mathrm{III})$.
\end{abstract}

\section{Introduction}

The behavior of lanthanides and actinides has received much attention in nuclear waste management $[1,2] . \mathrm{Eu}(\mathrm{III})$ is a trivalent lanthanide ion, and it is also a trivalent actinide chemical element homologue. A large number of $\mathrm{Eu}(\mathrm{III})$ exposure in the environment can cause great harm to people's health and life. Thus, the adsorption and migration of Eu(III) on metal oxides and minerals have been studied extensively, and the investigations of their potential pollution towards the natural water and soil environment are of great importance. $\mathrm{Xu}$ et al. studied the adsorption of $\mathrm{Eu}(\mathrm{III})$ on $\mathrm{TiO}_{2}$ with the presence of organic matters in different $\mathrm{pH}$ values, which indicated its adsorption behavior strongly influenced by the $\mathrm{pH}$ changes, and the adsorption mechanism was attributed to the formation of the inner ring complexes [3]. Wang et al. studied the adsorption of Eu(III) on alumina, which was also influenced by the $\mathrm{pH}$ changes, and the reaction is a surface complexation reaction [4]. Li et al. studied the adsorption of $\mathrm{Eu}(\mathrm{III})$ on iron oxides; the adsorption of Eu(III) was significantly dependent on $\mathrm{pH}$, temperature, and $\mathrm{HA}$ [5].
The carbon nanotube is a kind of carbon allotrope with typical layered hollow structure, and it is considered to be a typical one-dimensional material. Multiwalled carbon nanotubes (MWCNTs) are the coaxial tubes formed by several layers to dozens by hexagonal array of carbon atoms, with hybridization of carbon atoms in the tube wall, which can be easily modified; in addition, the carbon atoms exist as $\mathrm{SP}^{2}$ hybridization in the carbon nanotubes and form the most stable chemical bond $\mathrm{C}=\mathrm{C}$ covalent bond in nature [6]. Therefore, carbon nanotubes have excellent physiochemical property and versatile applications, especially in mechanics, electromagnetism, optics, electronics, catalysis, and composite materials fields, and have huge potential research value [7]. Due to its special structure, carbon nanotubes have large specific surface area and high chemical stability, and their surfaces can be functionalized easily [8], it is widely used in the adsorption process. Some researchers have done the study about metal ions (Pb(II), $\mathrm{Ni}(\mathrm{II})$, and $\mathrm{Cd}(\mathrm{II})$ ) adsorbed onto oMWCNTs in detail [9-11]. For example, Deng et al. studied the adsorption mechanism of PFCs (perfluorinated compounds) on MWCNTs [12]; their results indicated that 
MWCNTs have extremely excellent adsorption properties. And Sheng et al. [13] studied the adsorption of Eu(III) onto titanate nanotubes in microscopic insights.

Compared with experimental environment, the natural environment is more complicated [14]. There are few studies about the behavior of other organic materials on the adsorption of metal ions in the presence of carbon nanomaterials. Therefore, it is of great significance to study the effects of a variety of carbon nanomaterials coexisting on the adsorption of metal ions. In order to simulate the interactions of carbon nanomaterials with metal ions in a real environment, the organic matters are often selected as another study factors in the ternary system to study the adsorption of metal ions [1519]. In our study, the water-soluble fullerene was selected as the third element of the adsorption system to study its effect on $\mathrm{Eu}$ (III) adsorbed onto carbon nanotubes.

The fullerenes are following graphite, diamond, amorphous carbon, and another allotropes of carbon, which has broad applications in the gas storage, the field of optics, the polymer field, enhanced metals, superconducting field, battery materials, catalysts, and biological medical prospects [20]. As a fullerene, $\mathrm{C}_{60}$ is the cheapest and easiest to obtain, so $\mathrm{C}_{60}$ and its derivatives were used to investigate their properties in the current studies. Due to their large number of $\pi$ electrons, fullerene is very easy to form $\pi$ $\pi$ stacking with other aromatic materials $[21,22]$, then to affect its adsorption on metal ion or an organic. And adding the appropriate functional groups to the fullerene skeleton can improve the poor solubility [23]. Therefore, studying the effect of water-soluble fullerene on adsorption of $\mathrm{Eu}$ (III) onto carbon nanotubes can provide a new method for the study of trivalent lanthanides and actinides behavior, explore a variety of factors, and provide a theoretical basis for the long-lived radioactive waste disposal security issues.

\section{Materials and Methods}

2.1. Materials. Multiwall carbon nanotubes (L. MWNTs1030) materials, purity $>95 \%$ (amorphous carbon $\leq 3 \mathrm{wt} \%$, ash content $\leq 0.2 \mathrm{wt} \%$ ), with a diameter of $10-30 \mathrm{~nm}$, the length of $1-10 \mu \mathrm{m}$, specific surface area of $10-100 \mathrm{~m}^{2} / \mathrm{g}$, were purchased from Shenzhen Nanotech Port Company. Oxidation multi-walled carbon nanotubes were made by raw carbon nanotubes and concentrated nitric acid. First, 3 g MWCNTs were added into concentrated nitric acid $(400 \mathrm{~mL})$. The mixture was stirred at $80^{\circ} \mathrm{C}$ for $24 \mathrm{~h}$ then quenched with deionized water, and the product was collected. A mixture of concentrated nitric acid and concentrated sulfuric acid $(1: 3, \mathrm{~V} / \mathrm{V})(400 \mathrm{~mL})$ was added to the above compound and refluxed for $48 \mathrm{~h}$ then washed with deionized water $(\mathrm{pH}$ $\approx 6)$ to gain the oxidation multi-walled carbon nanotubes (oxidized MWCNTs, oMWCNTs) [26].

Fullerene $\left(\mathrm{C}_{60}\right)$, purity $>99.9 \%$, was purchased from Yongxin the fullerene Technology Co. Ltd. of Puyang City, Henan Province. The fullerene hydroxylation process was in accordance with the method of the literature [27]. In a $50 \mathrm{~mL}$ round bottom flask containing the benzene solution of $\mathrm{C}_{60}(1 \mathrm{mg} / \mathrm{mL})$, then added sodium hydroxide solution $(2 \mathrm{~mL}, 0.5 \mathrm{~mol} / \mathrm{L}), 5$ drops of $10 \%$ tetrabutylammonium hydroxide, and hydrogen peroxide ( $1 \mathrm{~mL}, 30 \%)$. The solution was stirred at room temperature for $12 \mathrm{~h}$ until the color of benzene solution changed from purple to colorless, and the aqueous solution changed from colorless to yellow-brown. The mixture was extracted to obtain a dark brown color of $\mathrm{C}_{60}(\mathrm{OH})_{x}(\mathrm{O})_{y}$ solution. After added methanol to the solution of $\mathrm{C}_{60}(\mathrm{OH})_{x}(\mathrm{O})_{y}$, the precipitation was occurred, then the precipitation was filtered, washed with water $(\mathrm{pH}<$ 8), and dried under vacuum. $\mathrm{C}_{60}(\mathrm{OH})_{n}$ was obtained [28].

Fullerene $\left(\mathrm{C}_{60}\right)$, purity $>99.9 \%$, was purchased from Yongxin the fullerene Technology Co. Ltd. of Puyang City, Henan Province. The $\mathrm{C}_{60}$ and $\mathrm{NaH}$ were added into toluene, when the color of the mixture solution changed from purple to deep red, then added diethyl bromomalonate. The residue was dissolved in the toluene, and then added $\mathrm{NaH}$ (excess 20 -fold than before). The solution was stirred at $80^{\circ} \mathrm{C}$ for $10 \mathrm{~h}$ under the protection of Ar gas and heating. Then, $\mathrm{CH}_{3} \mathrm{OH}$ was added to the solution to terminate the reaction immediately, and added $2 \mathrm{~mol} / \mathrm{L} \mathrm{HCl}$. The precipitate was filtered, collected, and washed by toluene, $2 \mathrm{~mol} / \mathrm{L} \mathrm{HCl}, \mathrm{H}_{2} \mathrm{O}$, and benzene [29].

Unless otherwise noted, materials were obtained from commercial suppliers and were used without further purification.

2.2. Batch Experiments. Determining the equilibrium time and the solid-liquid ratio, in a series of polyethylene centrifuge tube added a certain amount of oMWCNTs, $\mathrm{NaCl}$ and a known concentration $\mathrm{EuCl}_{3}$ solution, so that the various components of the system achieved the required concentration. The extremely small amount of $\mathrm{HCl}$ or $\mathrm{NaOH}$ solution can be added to the system to adjust the $\mathrm{pH}$ to a desired value. The samples were centrifuged $30 \mathrm{~min}$ at $12000 \mathrm{r} / \mathrm{min}$ after shaking $72 \mathrm{~h}$ in constant temperature. Taking out a certain volume supernatant, the supernatant counts were measured by a liquid scintillation counter. The adsorption of Eu(III) on the oMWCNTs was calculated by before and after the adsorption of Eu(III) in the liquid phase concentration.

2.3. X-Ray Photoelectron Spectroscopy (XPS) Analysis. In order to further analyze the molecular level information of the adsorbent material; the thermoelectric ESCALAB 250 spectrometer was used to identify the property of adsorbent material, the results were shown in Figure 1. The C1s peaks of oMWCNTs samples were at about 285.0, 288.2, and $289.0 \mathrm{eV}$ (Figure 1(a)), which were corresponding the $\mathrm{C}-\mathrm{C}, \mathrm{CO}$, and COO, respectively [30]. And O1s peaks of oMWCNTs sample at about 532.1, 534.1, and 537.2 eV (Figure 1(b)) were indicated the $\mathrm{OH}, \mathrm{OH} / \mathrm{CO}$, and $\mathrm{COO} / \mathrm{H}_{2} \mathrm{O}$, respectively [31]. C1s peaks of $\mathrm{C}_{60}(\mathrm{OH})_{n}$ at about 285.0 and $286.98 \mathrm{eV}$ (Figure $1(\mathrm{c})$ ) showed the $\mathrm{C}-\mathrm{C}$ and $\mathrm{COO}$, respectively O1s peak of $\mathrm{C}_{60}(\mathrm{OH})_{n}$ at $532.77 \mathrm{eV}$ (Figure $1(\mathrm{~d})$ ) was assigned to bridging $\mathrm{OH}$. Cls peak of $\mathrm{C}_{60}\left(\mathrm{C}(\mathrm{COOH})_{2}\right)_{n}$ at about 284.9 and $289.1 \mathrm{eV}$ (Figure 1(e)) was corresponding the $\mathrm{C}-\mathrm{C}$ and $\mathrm{COO}$, respectively. O1s peak of $\mathrm{C}_{60}\left(\mathrm{C}(\mathrm{COOH})_{2}\right)_{n}$ at about 532.4 and $533.5 \mathrm{eV}$ (Figure 1(f)) could be assigned to bridging $\mathrm{OH}$ and $\mathrm{COO} / \mathrm{H}_{2} \mathrm{O}$, respectively. The related peak areas are shown in Table 1. 


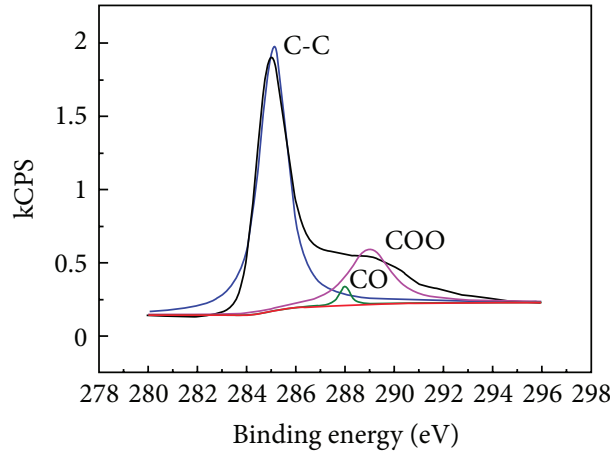

(a)

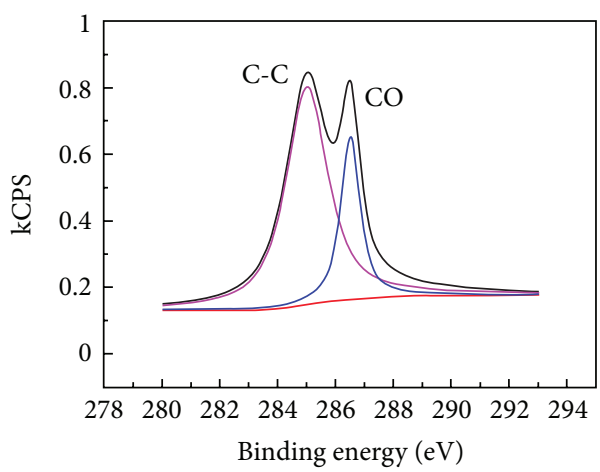

(c)

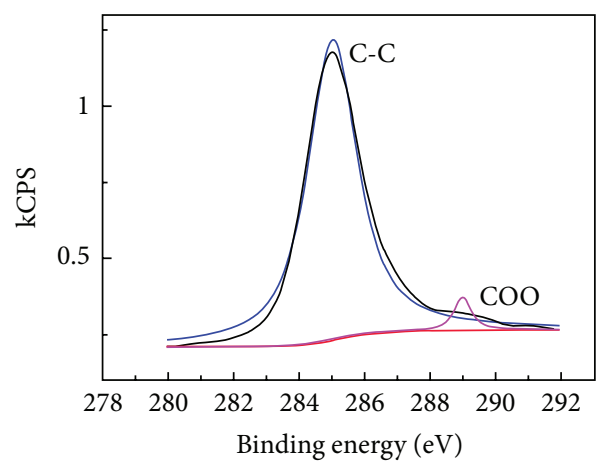

(e)

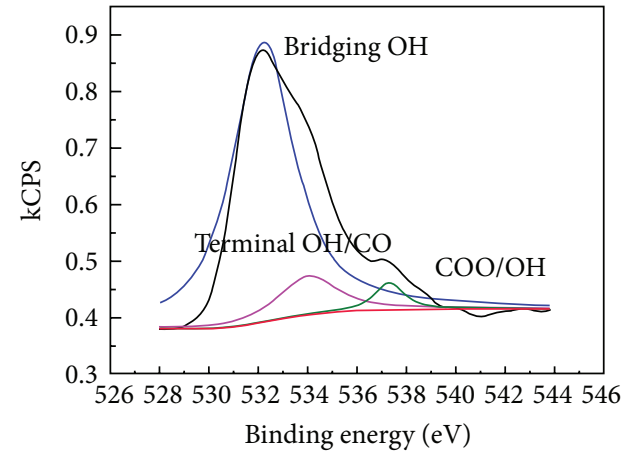

(b)

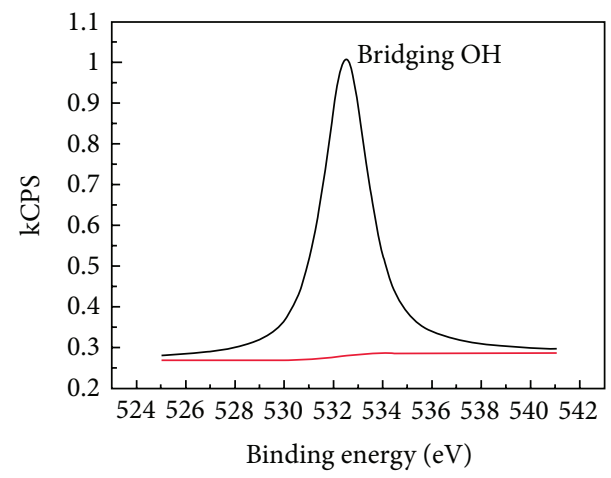

(d)

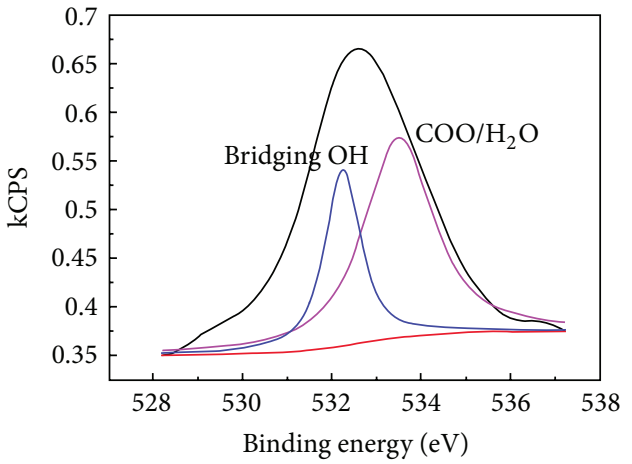

(f)

FIgure 1: The XPS of nanomaterials. (a) is the oMWCNTs C1s, (b) is oMWCNTs O1s, (c) is $\mathrm{C}_{60}(\mathrm{OH})_{n} \mathrm{Cls},(\mathrm{d})$ is $\mathrm{C}_{60}(\mathrm{OH})_{n} \mathrm{O} 1 \mathrm{~s},(\mathrm{e})$ is $\mathrm{C}_{60}\left(\mathrm{C}(\mathrm{COOH})_{2}\right)_{n} \mathrm{Cls}$, and (f) is $\mathrm{C}_{60}\left(\mathrm{C}(\mathrm{COOH})_{2}\right)_{n} \mathrm{O} 1 \mathrm{~s}$.

TABLE 1: The percentage of various functional groups on different carbon nanomaterials.

\begin{tabular}{lccc}
\hline Material & oMWCNTs & $\mathrm{C}_{60}(\mathrm{OH})_{n}$ & $\mathrm{C}_{60}\left(\mathrm{C}(\mathrm{COOH})_{2}\right)_{n}$ \\
\hline $\mathrm{C}-\mathrm{C}(\%)$ & 60.143 & 40.991 & 83.279 \\
$\mathrm{CO}(\%)$ & 16.098 & 21.555 & - \\
$\mathrm{COO}(\%)$ & 8.783 & - & - \\
Bridging OH (\%) & 8.575 & 17.739 & 16.721 \\
Terminal OH/CO (\%) & 6.400 & - & - \\
\hline
\end{tabular}

\section{Results and Discussions}

\subsection{Adsorption Kinetics}

3.1.1. Effect of Equilibrium Time on Eu(III) Adsorption onto oMWCNTs. The influence of the shaking time on $\mathrm{Eu}(\mathrm{III})$ adsorption onto oMWCNTs is shown in Figure 2. The adsorption ratio was increased with the increase of the shaking time. After $17 \mathrm{~h}$, the adsorption ratio of $\mathrm{Eu}(\mathrm{III})$ was close to $100 \%$; after that it was substantially unchanged. These results indicated that the adsorption of $\mathrm{Eu}$ (III) onto oMWCNTs was a chemical adsorption process [10]. The $48 \mathrm{~h}$ was selected as the equilibrium time in the following experiments.

3.1.2. Pseudo-Second-Order Equation. Quasi-second-order kinetic equation linear expression is

$$
\frac{t}{q_{t}}=\frac{1}{k q_{e}^{2}}+\frac{t}{q_{e}},
$$

where $q_{t}$ and $q_{e}$ denote the time $t$ and the equilibrium adsorption amount $(\mathrm{mg} / \mathrm{g})$ and $k$ is the second-order rate 


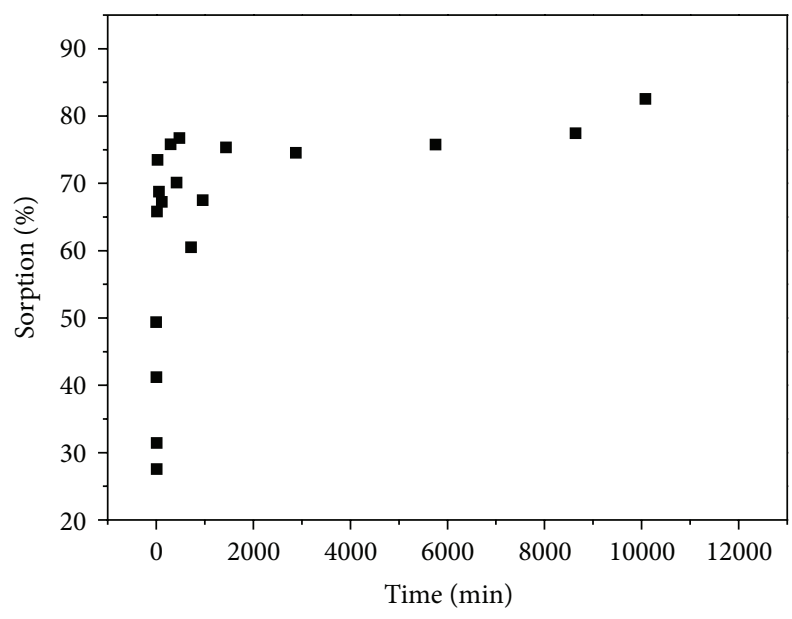

Figure 2: Effect of equilibrium time on Eu(III) adsorption onto oMWCNTs. $\mathrm{pH}=3.00 \pm 0.05, \mathrm{~m} / \mathrm{V}=0.0250 \mathrm{~g} / \mathrm{L}, \mathrm{T}=(25 \pm$ $1)^{\circ} \mathrm{C}, C_{\mathrm{Eu}}^{0}=1.21 \times 10^{-5} \mathrm{~mol} / \mathrm{L}$.

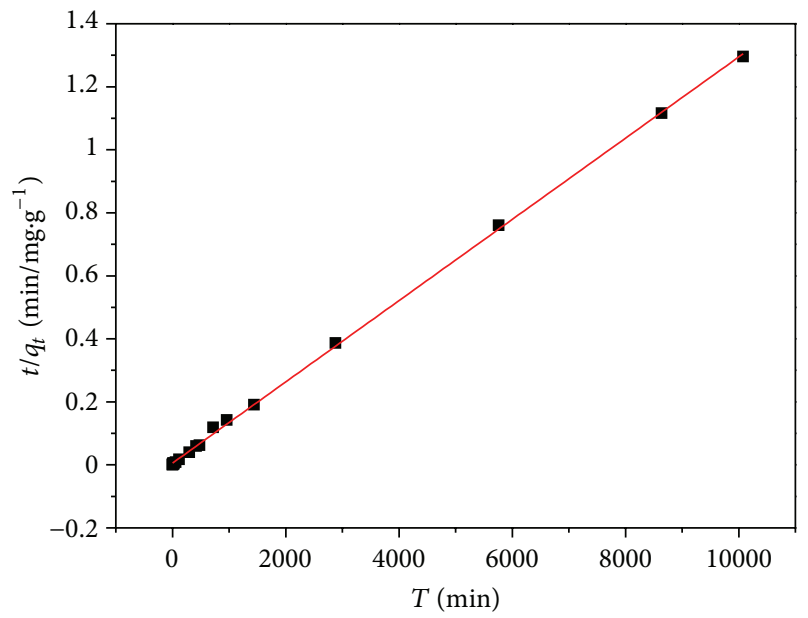

FIgURE 3: Pseudo-second-order sorption kinetics plot for $\mathrm{Eu}(\mathrm{III})$. $\mathrm{pH}=3.00 \pm 0.05, m / V=0.0250 \mathrm{~g} / \mathrm{L}, T=(25 \pm 1)^{\circ} \mathrm{C}, C_{\mathrm{Eu}}^{0}=1.21 \times$ $10^{-5} \mathrm{~mol} / \mathrm{L}$.

constant $\left(\mathrm{g} \cdot \mathrm{mg}^{-1} \cdot \mathrm{min}^{-1}\right)$. Using this equation to fit the experimental data, the results as shown in Figure 3, quasisecond-order equation is $y=0.00013 x+0.00552$, calculated by the slope and intercept of $k=3.3214 \times 10^{-3} \mathrm{~g} / \mathrm{mg} \cdot \mathrm{min}$, the $q_{e}=0.7757 \mathrm{mg} / \mathrm{g}$ and the linear correlation coefficient $R^{2}=0.9996$ which is almost 1 . These results showed that the adsorption of $\mathrm{Eu}$ (III) onto oMWCNTs was keeping with the quasi-second-order kinetic model.

3.2. Effect of $p H$ on $E u(I I I)$ Adsorption onto oMWCNTs. The influence of different $\mathrm{pH}$ on the adsorption was shown in Figure 4. Figure 4 shows that when the solid-liquid is $0.025 \mathrm{~g} / \mathrm{L}$ and ionic strength is $0.1 \mathrm{~mol} / \mathrm{L}(\mathrm{NaCl})$, the ratio of $\mathrm{Eu}(\mathrm{III})$ adsorption onto oMWCNTs is influenced strongly by the $\mathrm{pH}$. Figure 4 also shows the adsorption ratio of $\mathrm{Eu}$ (III) onto oMWCNTs declines with the ionic strength increases, suggesting that the adsorption can be suppressed by ionic

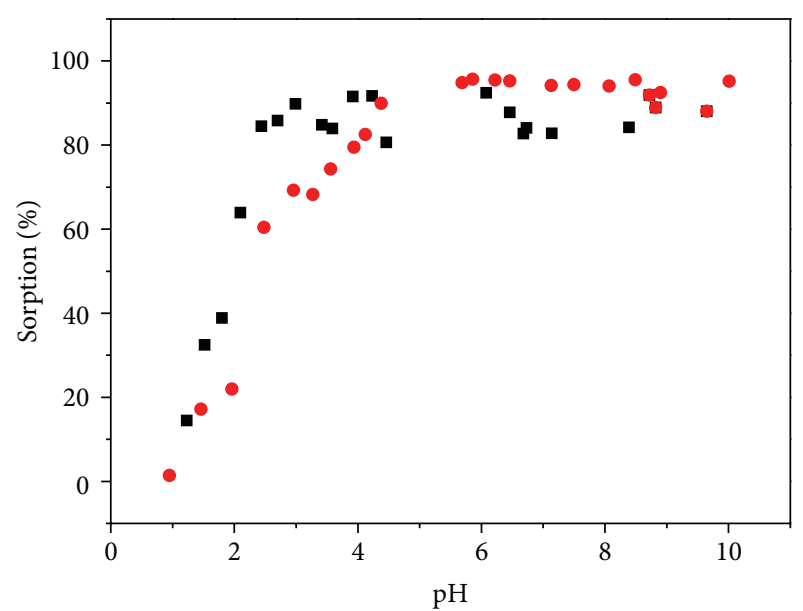

- $I=0.01 \mathrm{~mol} / \mathrm{L}$

$I=0.1 \mathrm{~mol} / \mathrm{L}$

FIgURE 4: Effect of $\mathrm{pH}$ on $\mathrm{Eu}(\mathrm{III})$ adsorption onto oMWCNTs. $m / V=0.0250 \mathrm{~g} / \mathrm{L}, T=(25 \pm 1)^{\circ} \mathrm{C}, C_{\mathrm{Eu}}^{0}=1.21 \times 10^{-5} \mathrm{~mol} / \mathrm{L}$.

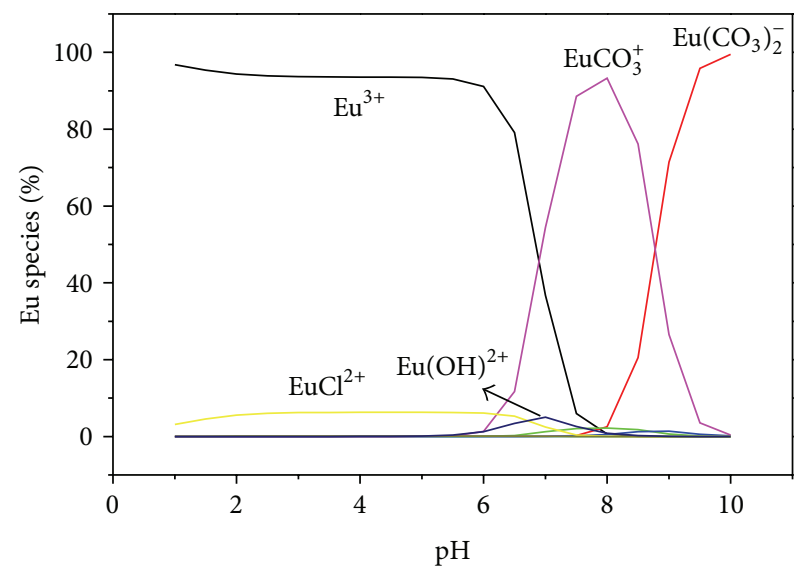

FIGURE 5: Relative species distribution of $\mathrm{Eu}(\mathrm{III}) . T=(25 \pm 1)^{\circ} \mathrm{C}$, $C_{\mathrm{Eu}}^{0}=1.21 \times 10^{-5} \mathrm{~mol} / \mathrm{L}, P_{\mathrm{CO}_{2}}=0.0038$.

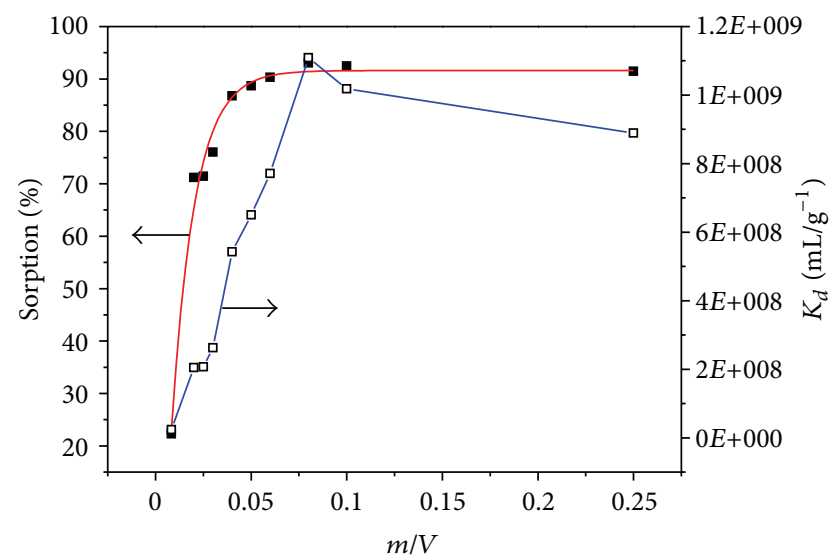

FIGURE 6: Effect of solid-to-liquid ratio of Eu(III) adsorption onto oMWCNTs. $\mathrm{pH}=3.00 \pm 0.05, m / V=0.0250 \mathrm{~g} / \mathrm{L}, T=(25 \pm 1)^{\circ} \mathrm{C}$, $C_{\mathrm{Eu}}^{0}=1.21 \times 10^{-5} \mathrm{~mol} / \mathrm{L}$. 


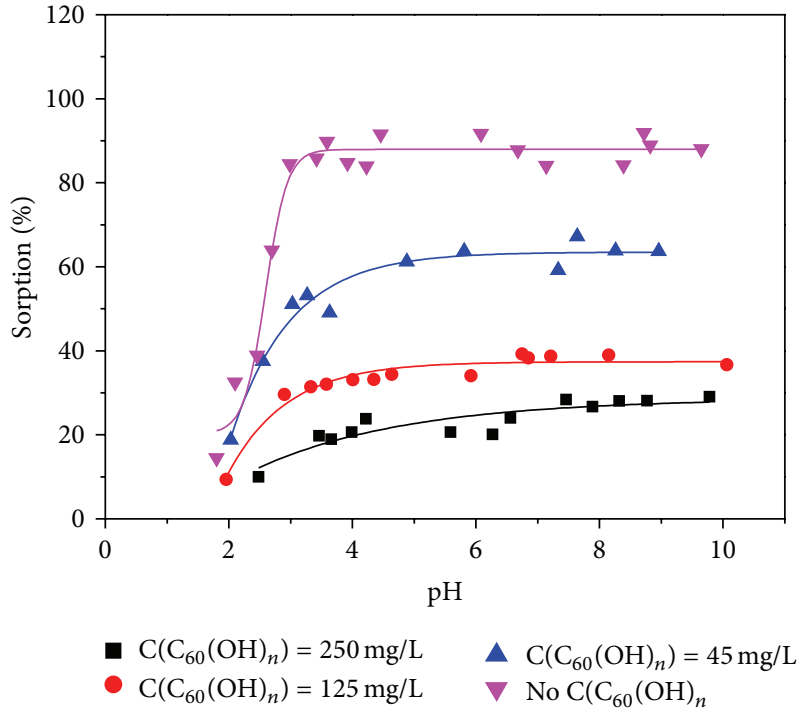

Figure 7: Effect of $\mathrm{C}_{60}(\mathrm{OH})_{n}$ on the adsorption of $\mathrm{Eu}(\mathrm{III})$ onto oMWCNTs. $\mathrm{pH}=3.00 \pm 0.05, m / V=0.025 \mathrm{~g} / \mathrm{L}, T=(25 \pm 1)^{\circ} \mathrm{C}$, $C_{\mathrm{Eu}}^{0}=1.21 \times 10^{-5} \mathrm{~mol} / \mathrm{L}$.

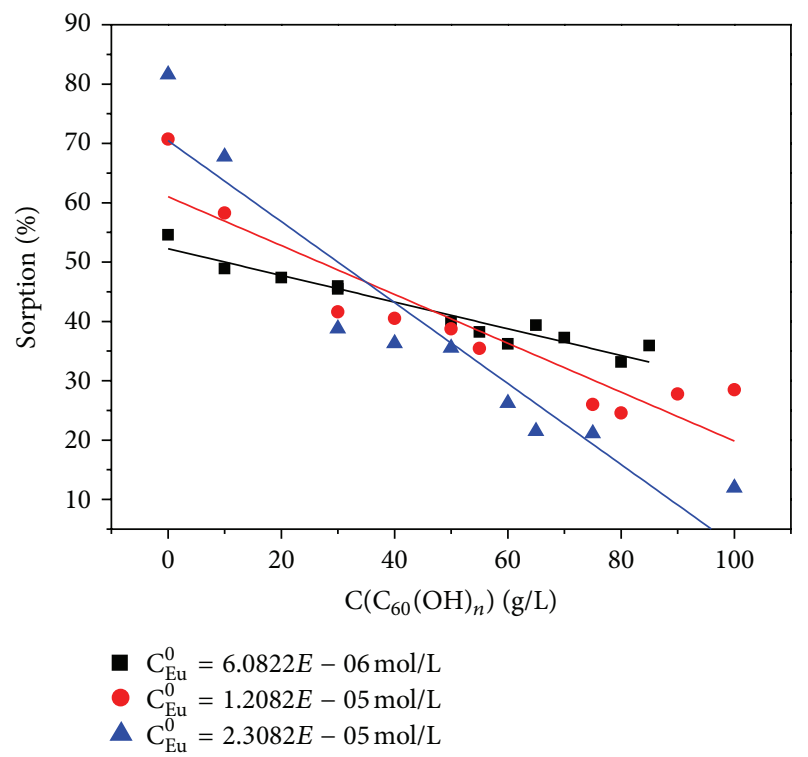

Figure 8: Effect of $\mathrm{Eu}(\mathrm{III})$ and $\mathrm{C}_{60}(\mathrm{OH})_{n}$ concentration on the adsorption of $\mathrm{Eu}$ (III) onto oMWCNTs. $\mathrm{pH}=3.00 \pm 0.05, \mathrm{~m} / \mathrm{V}=$ $0.025 \mathrm{~g} / \mathrm{L}, T=(25 \pm 1)^{\circ} \mathrm{C}, C_{\mathrm{Eu}}^{0}=1.21 \times 10^{-5} \mathrm{~mol} / \mathrm{L}$.

strength. Sheng et al. found that the adsorption rate of Th(IV) on raw diatomite increased rapidly to about $100 \%$ when the $\mathrm{pH}$ value changed from 2 to 4 and was influenced by the ionic strength strongly [13]. Wu et al., Guo et al., and Mingming et al. also found that the adsorption of $\mathrm{Eu}(\mathrm{III})$ on sodium bentonite and Na-attapulgite was effected by ionic strength and $\mathrm{pH}$ changes strongly [32-34]. The experimental results in this work further confirmed the previous results.

When $\mathrm{pH}<1.5$, the adsorption ratio was low and almost not changing with the $\mathrm{pH}$ increased. In the range $\mathrm{pH}$ of 1.5 to 4.0 , the adsorption ratio increased rapidly, from $20 \%$ to

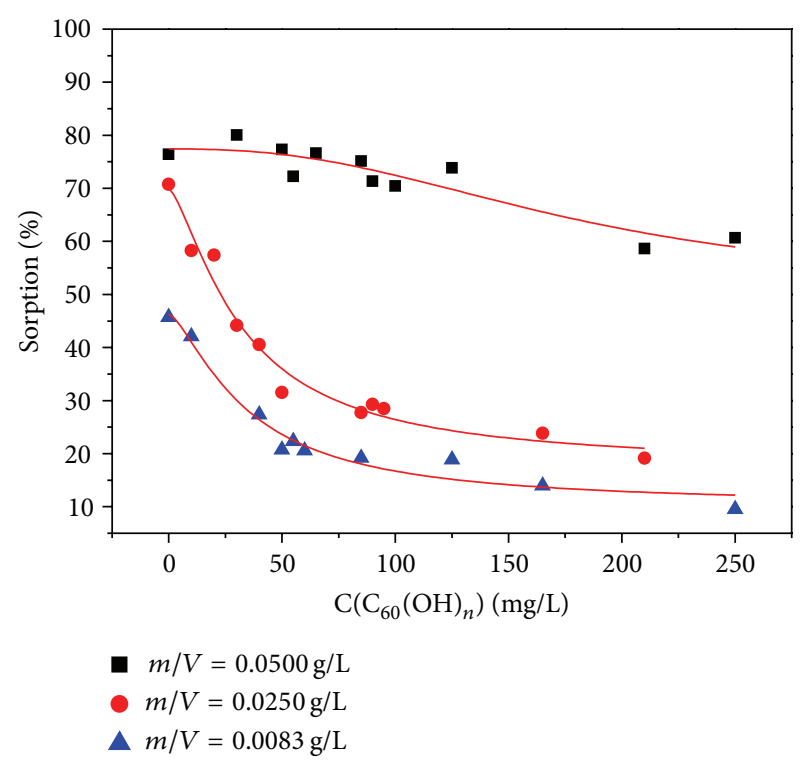

FIGURE 9: Effect of solid-liquid ratio and $\mathrm{C}_{60}(\mathrm{OH})_{n}$ concentration on the adsorption of $\mathrm{Eu}$ (III) onto oMWCNTs. $\mathrm{pH}=3.00 \pm$ $0.05, m / V=0.025 \mathrm{~g} / \mathrm{L}, T=(25 \pm 1)^{\circ} \mathrm{C}, C_{\mathrm{Eu}}^{0}=1.21 \times 10^{-5} \mathrm{~mol} / \mathrm{L}$.

about $90 \%$. When $\mathrm{pH}>4.0$, the adsorption ratio changed not so obviously indicating that the system was in equilibrium. Because the species distribution of $\mathrm{Eu}$ (III) can form a watersoluble carbonates at high $\mathrm{pH}$, so the adsorption ratio cannot reach $100 \%$.

The effect of $\mathrm{pH}$ on $\mathrm{Eu}(\mathrm{III})$ adsorption onto the oMWCNTs could be explained by the surface charge and ionization degree of oMWCNTs. When $\mathrm{pH}<\mathrm{pH}_{\mathrm{pzc}}, \mathrm{Eu}^{3+}$ and oMWCNTs surface proton produces electrostatic repulsion, which prevents $\mathrm{Eu}^{3+}$ from being adsorbed onto oMWCNTs, resulting in a lower adsorption ratio of $\mathrm{Eu}(\mathrm{III})$. When $\mathrm{pH}>\mathrm{pH}_{\mathrm{pzc}}, \mathrm{Eu}^{3+}$ interacts with oMWCNTs surface proton by electrostatic attraction making more $\mathrm{Eu}(\mathrm{III})$ adsorbed onto oMWCNTs surface, increasing the adsorption ratio of $\mathrm{Eu}(\mathrm{III})$. The species changes of $\mathrm{Eu}(\mathrm{III})$ with $\mathrm{pH}$ in solution is another important influencing factor for the adsorption system. The thermodynamic data used to estimate the $\mathrm{Eu}$ (III) species distribution in the solution were listed in Table 2. As shown in Figure 5, when the initial concentration of $\mathrm{Eu}(\mathrm{III})$ is $1.21 \times 10^{-5} \mathrm{~mol} / \mathrm{L}$ with background electrolyte $(0.01 \mathrm{~mol} / \mathrm{L} \mathrm{NaCl}$ solution $)$, the main existence forms are $\mathrm{Eu}^{3+}, \mathrm{Eu}(\mathrm{OH})_{2}{ }^{+}, \mathrm{EuCl}_{2}{ }^{+}, \mathrm{EuCO}_{3}{ }^{+}, \mathrm{Eu}\left(\mathrm{CO}_{3}\right)_{2}{ }^{-}$. When $\mathrm{pH} \leq$ 6.5 , the main species is $\mathrm{Eu}^{3+}$. When $\mathrm{pH}>6.5$, due to the impact of $\mathrm{CO}_{2}, \mathrm{Eu}$ (III) mainly exists as the forms of $\mathrm{EuCO}_{3}{ }^{+}$and $\mathrm{Eu}\left(\mathrm{CO}_{3}\right)_{2}{ }^{-}$in solution, which have relatively low solubility in aqueous solution leading to increase $\mathrm{Eu}(\mathrm{III})$ content in the solid phase, so the adsorption ratio of $\mathrm{Eu}(\mathrm{III})$ onto oMWCNTs maintains the maximum and no longer changes.

3.3. Effect of Solid-Liquid Ratio on Eu(III) Adsorption onto $o M W C N T$. Figure 6 shows that the adsorption ratio transformation of $\mathrm{Eu}(\mathrm{III})$ adsorption onto oMWCNTs increases 
TABLE 2: The thermodynamic constants used for species estimates $[24,25]$.

\begin{tabular}{lc}
\hline Reaction & $\log K$ \\
\hline $\mathrm{H}_{2} \mathrm{O} \leftrightarrow \mathrm{OH}^{-}+\mathrm{H}^{+}$ & -13.8 \\
$\mathrm{Eu}^{3+}+\mathrm{H}_{2} \mathrm{O} \leftrightarrow[\mathrm{Eu}(\mathrm{OH})]^{2+}+\mathrm{H}^{+}$ & -7.64 \\
$\mathrm{Eu}^{3+}+2 \mathrm{H}_{2} \mathrm{O} \leftrightarrow\left[\mathrm{Eu}(\mathrm{OH})_{2}\right]^{+}+2 \mathrm{H}^{+}$ & -15.1 \\
$\mathrm{Eu}^{3+}+3 \mathrm{H}_{2} \mathrm{O} \leftrightarrow\left[\mathrm{Eu}(\mathrm{OH})_{3}\right]^{0}+3 \mathrm{H}^{+}$ & -23.7 \\
$\mathrm{Eu}^{3+}+4 \mathrm{H}_{2} \mathrm{O} \leftrightarrow\left[\mathrm{Eu}(\mathrm{OH})_{4}\right]^{-}+4 \mathrm{H}^{+}$ & -36.2 \\
$\mathrm{H}_{2} \mathrm{CO}_{3} \leftrightarrow \mathrm{CO}_{3}{ }^{2-}+2 \mathrm{H}^{+}$ & -17.43 \\
$\mathrm{Eu}^{3+}+\mathrm{CO}_{3}{ }^{2-} \leftrightarrow[\mathrm{EuCO}]^{+}$ & 8.1 \\
$\mathrm{Eu}^{3+}+2 \mathrm{CO}_{3}{ }^{2-} \leftrightarrow\left[\mathrm{Eu}\left(\mathrm{CO}_{3}\right)_{2}\right]^{-}$ & 12.1 \\
$\mathrm{Eu}^{3+}+\mathrm{Cl}^{-} \leftrightarrow \mathrm{EuCl}^{2+}$ & 1.10 \\
$\mathrm{Eu}^{3+}+2 \mathrm{Cl}^{-} \leftrightarrow \mathrm{EuCl}_{2}{ }^{+}$ & 1.50 \\
\hline
\end{tabular}

with the increasing of oMWCNTs concentration. With the increasing of the solid solution ratio in the system, the adsorption ratio of $\mathrm{Eu}(\mathrm{III})$ is increasing until $\mathrm{Eu}(\mathrm{III})$ is adsorbed completely. While the percentage composition of oMWCNTs increases, the surface adsorption sites also increase, which can promote the adsorption of $\mathrm{Eu}(\mathrm{III})$. Figure 6 also shows the influence of different $m / V$ value on the distribution coefficient $K_{d} . K_{d}$ values can be estimated by $C_{s}$ and $C_{e}$ :

$$
K_{d}=\frac{C_{s}-C_{e}}{C_{e}} \cdot \frac{V}{m},
$$

where $V$ is the volume of the solution $(\mathrm{m} / \mathrm{L})$ and $m$ is the weight of solid (g). As shown in Figure 6, with the increasing of the solid-liquid ratio, $K_{d}$ values also increase gradually, when the solid-liquid ratio exceeds $0.1 \mathrm{~mL} / \mathrm{g}, K_{d}$ value declines slightly. Thus, it can be seen from that, $K_{d}$ value depends on the solid content at low solid concentration, but when the solid content reaches a certain concentration, $K_{d}$ value is never depend on the solid content. This phenomenon also presents in the adsorption system of the other metal ions and the different adsorbents $[35,36]$.

3.4. Effect of $\mathrm{C}_{60}(\mathrm{OH})_{n}$ on $\mathrm{Eu}(\mathrm{III})$ Adsorption onto oMWCNTs. Figure 7 shows the Eu(III) adsorption border changes in the present of different $\mathrm{C}_{60}(\mathrm{OH})_{n}$ concentration. When the concentration of $\mathrm{C}_{60}(\mathrm{OH})_{n}$ is $250 \mathrm{mg} / \mathrm{L}$, the adsorption capacity of $\mathrm{Eu}$ (III) on the oMWCNTs is about $10 \%$ at $\mathrm{pH} 2.5$, but it arrives at about $28 \%$ at $\mathrm{pH} 7$. While the concentration of $\mathrm{C}_{60}(\mathrm{OH})_{n}$ is $125 \mathrm{mg} / \mathrm{L}$, the adsorption rate increases significantly, which rises from $20 \%$ at $\mathrm{pH} 2.5$ to $38 \%$ at $\mathrm{pH}$ 6.8. Similarly, when the concentration of $\mathrm{C}_{60}(\mathrm{OH})_{n}$ is $45 \mathrm{mg} / \mathrm{L}$, the adsorption of $\mathrm{C}_{60}(\mathrm{OH})_{n}$ reaches the maximum at the same $\mathrm{pH}$ value. These results show that the presence of $\mathrm{C}_{60}(\mathrm{OH})_{n}$ can restrain the adsorption of $\mathrm{Eu}$ (III) onto oMWCNTs. According to the literatures, in a ternary system, the organic material plays an important role in metal ions adsorbed onto oMWCNTs. It is mainly attributed to the ternary complex which was formed by metal ion, the organics, and the surface functional groups of oMWCNTs through hydrophobic interactions, electrostatic interactions, and hydrogen bonds [37, 38]. But

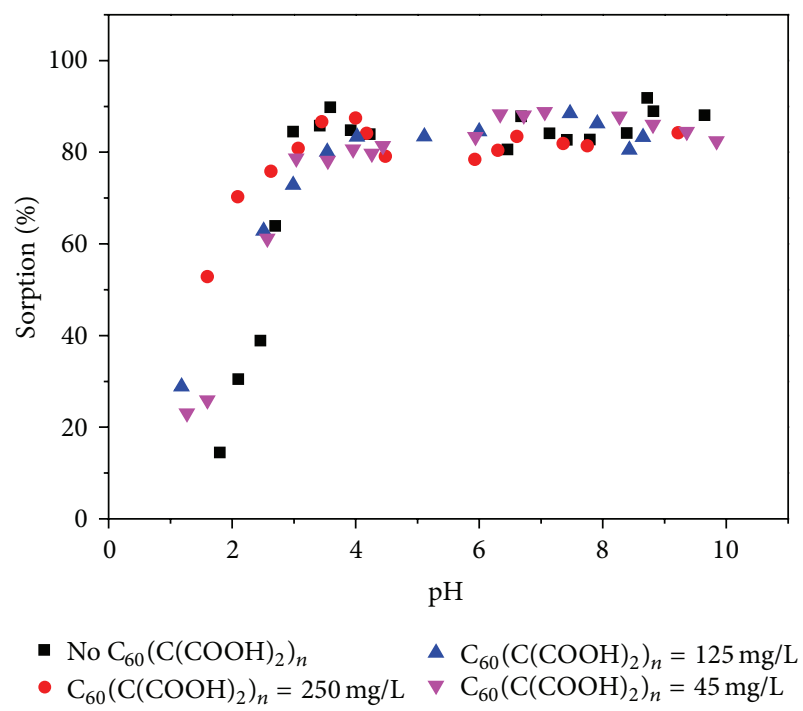

Figure 10: Effect of $\mathrm{C}_{60}(\mathrm{OH})_{n}$ on the adsorption of $\mathrm{Eu}(\mathrm{III})$ onto oMWCNTs. $\mathrm{pH}=3.00 \pm 0.05, \mathrm{~m} / \mathrm{V}=0.025 \mathrm{~g} / \mathrm{L}, \mathrm{T}=(25 \pm 1)^{\circ} \mathrm{C}$, $C_{\mathrm{Eu}}^{0}=1.21 \times 10^{-5} \mathrm{~mol} / \mathrm{L}$.

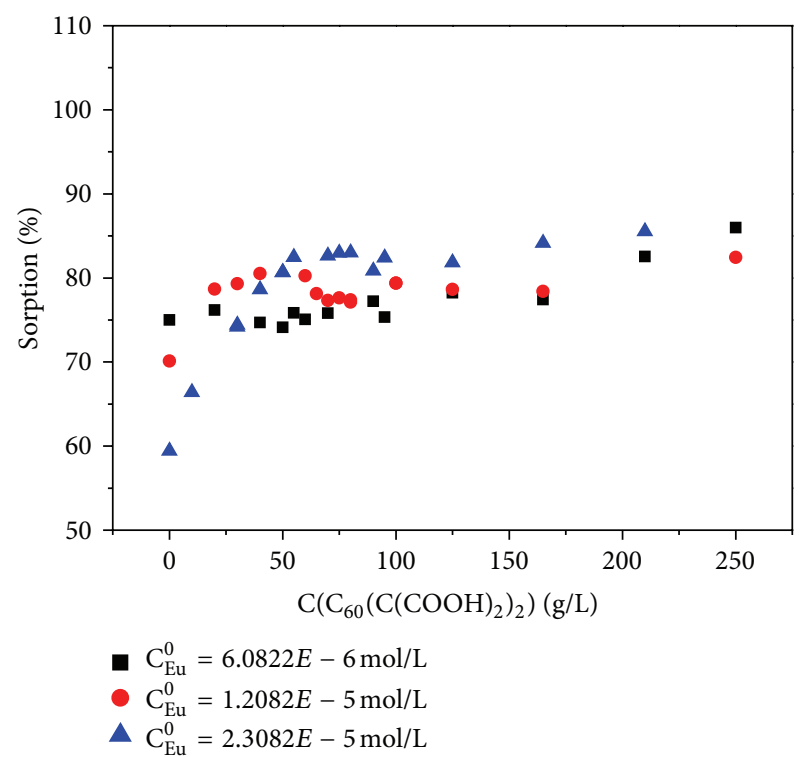

FIgURE 11: Effect of $\mathrm{Eu}(\mathrm{III})$ initial concentrations and $\mathrm{C}_{60}$ $\left(\mathrm{C}(\mathrm{COOH})_{2}\right)_{2}$ concentrations on $\mathrm{Eu}(\mathrm{III})$ adsorption onto oMWCNTs. $\mathrm{pH}=3.00 \pm 0.05, m / V=0.025 \mathrm{~g} / \mathrm{L}, T=(25 \pm 1)^{\circ} \mathrm{C}$, $C_{\mathrm{Eu}}^{0}=1.21 \times 10^{-5} \mathrm{~mol} / \mathrm{L}$.

$\mathrm{C}_{60}(\mathrm{OH})_{n}$ can compete with $\mathrm{Eu}(\mathrm{III})$ for the surface adsorption sites of oMWCNTs, which could weaken the adsorption ratio of $\mathrm{Eu}$ (III) onto oMWCNTs. With the concentration of $\mathrm{C}_{60}(\mathrm{OH})_{n}$ increasing gradually, more and more $\mathrm{C}_{60}(\mathrm{OH})_{n}$ is connected to oMWCNTs. So $\mathrm{C}_{60}(\mathrm{OH})_{n}$ could affect the surface properties of oMWCNTs as well as the adsorption sites, then the adsorption ratio of $\mathrm{Eu}(\mathrm{III})$ onto oMWCNTs is decreased. For further understanding of the effect of $\mathrm{C}_{60}(\mathrm{OH})_{n}$ on the adsorption system, changing the initial concentration of $\mathrm{Eu}(\mathrm{III})$ and solid-liquid ratio to observe 


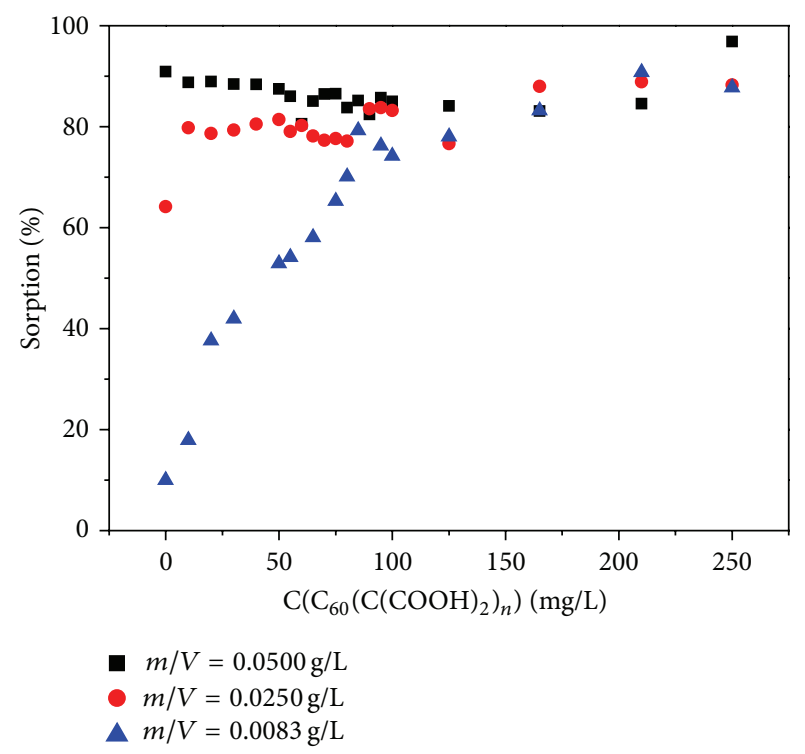

FIgUre 12: Effect of oMWCNTs solid-liquid ratio and $\mathrm{C}_{60}$ $\left(\mathrm{C}(\mathrm{COOH})_{2}\right)_{2}$ concentrations on the adsorption of $\mathrm{Eu}(\mathrm{III})$ onto oMWCNTs. pH $=3.00 \pm 0.05, m / V=0.025 \mathrm{~g} / \mathrm{L}, T=(25 \pm 1)^{\circ} \mathrm{C}$, $C_{\mathrm{Eu}}^{0}=1.21 \times 10^{-5} \mathrm{~mol} / \mathrm{L}$

the effects of different $\mathrm{C}_{60}(\mathrm{OH})_{n}$ concentrations on $\mathrm{Eu}(\mathrm{III})$ adsorption onto oMWCNTs was investigated (Figures 8 and 9). It indicates that the $\mathrm{Eu}(\mathrm{III})$ is only adsorbed on oMWCNTs surface with no interaction with $\mathrm{C}_{60}(\mathrm{OH})_{n}$. As shown in Figure 8 , when the initial concentration of $\mathrm{Eu}(\mathrm{III})$ is $6.0822 \times$ $10^{-6} \mathrm{~mol} / \mathrm{L}$, the adsorption rate becomes smaller gradually with $\mathrm{C}_{60}(\mathrm{OH})_{n}$ concentration increases. The result shows that $\mathrm{Eu}$ (III) is adsorbed by oMWCNTs before the interaction of oMWCNTs with $\mathrm{C}_{60}(\mathrm{OH})_{n}$ due to the low concentration of $\mathrm{Eu}(\mathrm{III})$, Conversely, when the initial concentration of the $\mathrm{Eu}(\mathrm{III})$ is increased to $2.3082 \times 10^{-5} \mathrm{~mol} / \mathrm{L}$, under the same concentration of oMWCNTs and $\mathrm{C}_{60}(\mathrm{OH})_{n}$, the adsorption ratio is increases gradually because the abundant $\mathrm{Eu}(\mathrm{III})$ is enough strong to compete with $\mathrm{C}_{60}(\mathrm{OH})_{n}$ for oMWCNTs. Figure 9 shows that when the solid-liquid ratio is $0.0250 \mathrm{~g} / \mathrm{L}$ or $0.0083 \mathrm{~g} / \mathrm{L}$, and the concentration of $\mathrm{C}_{60}(\mathrm{OH})_{n}$ is less than $150 \mathrm{mg} / \mathrm{L}$, the adsorption ratio of $\mathrm{Eu}(\mathrm{III})$ declines sharply, and then with the increasing of $\mathrm{C}_{60}(\mathrm{OH})_{n}$, the adsorption rate becomes slow and till to stable. However, when the solid-liquid ratio rises to $0.0500 \mathrm{~g} / \mathrm{L}$, the adsorption rate of $\mathrm{Eu}$ (III) is slowly decreased, but it is higher than that of the solid-liquid ratio is $0.0250 \mathrm{~g} / \mathrm{L}$ and $0.0083 \mathrm{~g} / \mathrm{L}$. This is because that with the increasing of solid-liquid ratio, the available adsorption sites also increases, so more $\mathrm{Eu}(\mathrm{III})$ is adsorbed to oMWCNTs.

3.5. Effect of $\mathrm{C}_{60}\left(\mathrm{C}(\mathrm{COOH})_{2}\right)_{2}$ on $\mathrm{Eu}(\mathrm{III})$ Adsorption onto oMWCNTs. The effect of $\mathrm{C}_{60}\left(\mathrm{C}(\mathrm{COOH})_{2}\right)_{2}$ on the adsorption of $\mathrm{Eu}(\mathrm{III})$ is shown in Figure 10. The presence of $\mathrm{C}_{60}\left(\mathrm{C}(\mathrm{COOH})_{2}\right)_{2}$ promoted the adsorption of the $\mathrm{Eu}(\mathrm{III})$ onto the oMWCNTs in the $\mathrm{pH}$ range of 1.5 to 3.5 significantly, and the maximum adsorption ratio is observed at $\mathrm{pH}>3.5$. Considering the ability of $\pi-\pi$ stacking between $\mathrm{C}_{60}\left(\mathrm{C}(\mathrm{COOH})_{2}\right)_{2}$ and oMWCNTs is less than that of $\mathrm{C}_{60}(\mathrm{OH})_{n}$, and the space steric effect of $\mathrm{C}_{60}\left(\mathrm{C}(\mathrm{COOH})_{2}\right)_{2}$ is stronger than that of $\mathrm{C}_{60}(\mathrm{OH})_{n}$, so the adsorption capacity of $\mathrm{C}_{60}\left(\mathrm{C}(\mathrm{COOH})_{2}\right)_{2}$ onto the surface of oMWCNTs is not as large as $\mathrm{C}_{60}(\mathrm{OH})_{n}$, which provides more opportunities for Eu(III) to be adsorbed by oMWCNTs. Under the acidic environment, $\mathrm{C}_{60}\left(\mathrm{C}(\mathrm{COOH})_{2}\right)_{2}$ is very easy to combine with $\mathrm{H}^{+}$from the solution and oMWCNTs surface, so Eu(III) is adsorbed onto the surface of oMWCNTs more easily. Meanwhile, the presence of hydrolyzate of Eu(III) may also be another reason to increase the adsorption ratio.

Similarly, changing the initial concentration of $\mathrm{Eu}(\mathrm{III})$ and the ratio of solid to liquid at $\mathrm{pH} 3.00 \pm 0.05$, the effect of $\mathrm{C}_{60}\left(\mathrm{C}(\mathrm{COOH})_{2}\right)_{2}$ concentration on the adsorption ratio is shown in Figures 11 and 12. As shown in Figure 11, when the initial concentration of Eu(III) is $6.0822 \times 10^{-6} \mathrm{~g} / \mathrm{L}$, there are enough adsorption sites to be occupied by Eu(III), and the adsorption ratio can reach maximum value fast. However, when the initial concentration of Eu(III) is $2.3082 \times$ $10^{-5} \mathrm{~g} / \mathrm{L}$, the adsorption sites of oMWCNTs are occupied completely at absence of $\mathrm{C}_{60}\left(\mathrm{C}(\mathrm{COOH})_{2}\right)_{2}$, and the adsorption ratio is low; but once the $\mathrm{C}_{60}\left(\mathrm{C}(\mathrm{COOH})_{2}\right)_{2}$ is added, the $\mathrm{C}_{60}\left(\mathrm{C}(\mathrm{COOH})_{2}\right)_{2}$ can improve $\mathrm{Eu}(\mathrm{III})$ adsorption onto oMWCNTs, thus the adsorption ratio is increased with the increasing of $\mathrm{C}_{60}\left(\mathrm{C}(\mathrm{COOH})_{2}\right)_{2}$ concentration until to the maximum, and then maintains this level. As shown in Figure 12, for the low solid-liquid ratio, such as $m / V=$ $0.0083 \mathrm{~g} / \mathrm{L}$ or $0.025 \mathrm{~g} / \mathrm{L}$, the quantity of Eu(III) in the solution are so much more than the adsorption sites of oMWCNTs. After the adsorption process is in the equilibrium at the experimental conditions, the solid-liquid ratio is low, and the sorption ratio also is low. However, when the $\mathrm{C}_{60}\left(\mathrm{C}(\mathrm{COOH})_{2}\right)_{2}$ presents at the adsorption system, the adsorption ratio is increased due to $\mathrm{C}_{60}\left(\mathrm{C}(\mathrm{COOH})_{2}\right)_{2}$ can promote the adsorption of $\mathrm{Eu}(\mathrm{III})$ onto oMWCNTs. And with the increasing of the concentration of $\mathrm{C}_{60}\left(\mathrm{C}(\mathrm{COOH})_{2}\right)_{2}$, the adsorption ratio is increased till the $\mathrm{Eu}(\mathrm{III})$ adsorbed completely.

\section{Conclusion}

The effects and behavior of $\mathrm{Eu}(\mathrm{III})$ adsorption onto oMWCNTs are studied when the $\mathrm{C}_{60}\left(\mathrm{C}(\mathrm{COOH})_{2}\right)_{2}$ or $\mathrm{C}_{60}(\mathrm{OH})_{n}$ is added. The adsorption of $\mathrm{Eu}(\mathrm{III})$ onto oMWCNTs is affected strongly by $\mathrm{pH}$ and ionic strength. The presence of $\mathrm{C}_{60}\left(\mathrm{C}(\mathrm{COOH})_{2}\right)_{n}$ promotes the changes of adsorption ratio obviously. However, $\mathrm{C}_{60}(\mathrm{OH})_{n}$ competes the adsorption sites with $\mathrm{Eu}(\mathrm{III})$, leading to reducing the adsorption ratio of $\mathrm{Eu}(\mathrm{III})$ adsorbed onto oMWCNTs.

\section{References}

[1] X. Tan, Q. Fan, X. Wang, and B. Grambow, "Eu(III) sorption to $\mathrm{TiO}_{2}$ (anatase and rutile): batch, XPS, and EXAFS studies," Environmental Science and Technology, vol. 43, no. 9, pp. 31153121, 2009.

[2] G. Montavon, S. Markai, Y. Andrés, and B. Grambow, "Complexation studies of Eu(III) with alumina-bound polymaleic 
acid: effect of organic polymer loading and metal ion concentration," Environmental Science and Technology, vol. 36, no. 15, pp. 3303-3309, 2002.

[3] J. Z. Xu, Q. Fan, Z. Niu, Y. Li, P. Li, and W. Wu, "Studies of Eu(III) sorption on $\mathrm{TiO}_{2}$ : effects of $\mathrm{pH}$, humic acid and poly(acrylic acid)," Chemical Engineering Journal, vol. 179, pp. 186-192, 2012.

[4] X. Wang, D. Xu, L. Chen et al., "Sorption and complexation of $\mathrm{Eu}$ (III) on alumina: effects of $\mathrm{pH}$, ionic strength, humic acid and chelating resin on kinetic dissociation study," Applied Radiation and Isotopes, vol. 64, no. 4, pp. 414-421, 2006.

[5] P. Li, Q. Fan, D. Pan, S. Liu, and W. Wu, "Effects of pH, ionic strength, temperature, and humic acid on Eu(III) sorption onto iron oxides," Journal of Radioanalytical and Nuclear Chemistry, vol. 289, no. 3, pp. 757-764, 2011.

[6] S. Iijima, "Helical microtubules of graphitic carbon," Nature, vol. 354, no. 6348, pp. 56-58, 1991.

[7] J. R. Heath, "Nanoscale materials," Accounts of Chemical Research, vol. 32, no. 5, p. 388, 1999.

[8] A. Abbaspour and A. Izadyar, "Carbon nanotube composite coated platinum electrode for detection of $\mathrm{Cr}$ (III) in real samples," Talanta, vol. 71, no. 2, pp. 887-892, 2007.

[9] D. Xu, X. Tan, C. Chen, and X. Wang, "Removal of Pb(II) from aqueous solution by oxidized multiwalled carbon nanotubes," Journal of Hazardous Materials, vol. 154, no. 1-3, pp. 407-416, 2008.

[10] S. Yang, J. Li, D. Shao, J. Hu, and X. Wang, "Adsorption of $\mathrm{Ni}(\mathrm{II})$ on oxidized multi-walled carbon nanotubes: effect of contact time, $\mathrm{pH}$, foreign ions and PAA," Journal of Hazardous Materials, vol. 166, no. 1, pp. 109-116, 2009.

[11] X. Tian, T. Li, K. Yang, Y. Xu, H. Lu, and D. Lin, "Effect of humic acids on physicochemical property and $\mathrm{Cd}(\mathrm{II})$ sorption of multiwalled carbon nanotubes," Chemosphere, vol. 89, no. 11, pp. 1316-1322, 2012.

[12] S. Deng, Q. Zhang, Y. Nie et al., "Sorption mechanisms of perfluorinated compounds on carbon nanotubes," Environmental Pollution, vol. 168, pp. 138-144, 2012.

[13] G. Sheng, J. Hu, and X. Wang, "Sorption properties of Th(IV) on the raw diatomite-effects of contact time, $\mathrm{pH}$, ionic strength and temperature," Applied Radiation and Isotopes, vol. 66, no. 10, pp. 1313-1320, 2008.

[14] H. Hyung and J. H. Kim, "Natural organic matter (NOM) adsorption to multi-walled carbon nanotubes: effect of NOM characteristics and water quality parameters," Environmental Science and Technology, vol. 42, no. 12, pp. 4416-4421, 2008.

[15] W. Xiangke, D. Wenming, D. Xiongxin, W. Aixia, D. Jinzhou, and T. Zuyi, "Sorption and desorption of Eu and Yb on alumina: mechanisms and effect of fulvic acid," Applied Radiation and Isotopes, vol. 52, no. 2, pp. 165-173, 2000.

[16] S. Wang, J. Hu, J. Li, and Y. Dong, "Influence of $\mathrm{pH}$, soil humic/fulvic acid, ionic strength, foreign ions and addition sequences on adsorption of $\mathrm{Pb}(\mathrm{II})$ onto GMZ bentonite," Journal of Hazardous Materials, vol. 167, no. 1-3, pp. 44-51, 2009.

[17] A. B. M. Giasuddin, S. R. Kanel, and H. Choi, "Adsorption of humic acid onto nanoscale zerovalent iron and its effect on arsenic removal," Environmental Science and Technology, vol. 41, no. 6, pp. 2022-2027, 2007.

[18] C. Chen and X. Wang, "Sorption of Th (IV) to silica as a function of $\mathrm{pH}$, humic/fulvic acid, ionic strength, electrolyte type," Applied Radiation and Isotopes, vol. 65, no. 2, pp. 155-163, 2007.
[19] T. J. Strathmann and S. C. B. Myneni, "Effect of soil fulvic acid on nickel(II) sorption and bonding at the aqueous-boehmite ( $\gamma$ AIOOH) interface," Environmental Science and Technology, vol. 39, no. 11, pp. 4027-4034, 2005.

[20] R. B. Sardenberg, C. E. Teixeira, M. Pinheiro, and J. M. A. Figueiredo, "Nonlinear conductivity of fullerenol aqueous solutions," ACS Nano, vol. 5, no. 4, pp. 2681-2686, 2011.

[21] M. Bühl and A. Hirsch, "Spherical aromaticity of fullerenes," Chemical Reviews, vol. 101, no. 5, pp. 1153-1183, 2001.

[22] M. A. Montes-Morán, D. Suárez, J. A. Menéndez, and E. Fuente, "On the nature of basic sites on carbon surfaces: an overview," Carbon, vol. 42, no. 7, pp. 1219-1225, 2004.

[23] P. A. Troshin, H. Hoppe, J. Renz et al., "Material solubilityphotovoltaic performance relationship in the design of novel fullerene derivatives for bulk heterojunction solar cells," Advanced Functional Materials, vol. 19, no. 5, pp. 779-788, 2009.

[24] M. H. Bradbury and B. Baeyens, "Sorption of Eu on Na- and Camontmorillonites: experimental investigations and modelling with cation exchange and surface complexation," Geochimica et Cosmochimica Acta, vol. 66, no. 13, pp. 2325-2334, 2002.

[25] H. Geckeis, T. Rabung, T. N. Manh, J. I. Kim, and H. P. Beck, "Humic colloid-borne natural polyvalent metal ions: dissociation experiment," Environmental Science and Technology, vol. 36, no. 13, pp. 2946-2952, 2002.

[26] F. Avilés, J. V. Cauich-Rodríguez, L. Moo-Tah, A. May-Pat, and R. Vargas-Coronado, "Evaluation of mild acid oxidation treatments for MWCNT functionalization," Carbon, vol. 47, no. 13, pp. 2970-2975, 2009.

[27] T. Li, X. Li, K. Huang, H. Jiang, and J. Li, "Synthesis and characterization of hydroxylated fullerene epoxide-an intermediate for forming fullerol," Journal of Central South University of Technology, vol. 6, no. 1, pp. 35-36, 1999.

[28] J. Y. Xu, H. Kaiyu, S. Li et al., "Pulmonary responses to polyhydroxylated fullerenols, $\mathrm{C}_{60}(\mathrm{OH})_{x}$," Journal of Applied Toxicology, vol. 29, no. 7, pp. 578-584, 2009.

[29] F. Cheng, X. Yang, H. Zhu, J. Sun, and Y. Liu, "Synthesis of oligoadducts of malonic acid $\mathrm{C}_{60}$ and their scavenging effects on hydroxyl radical," Journal of Physics and Chemistry of Solids, vol. 61, no. 7, pp. 1145-1148, 2000.

[30] H. Wang, A. Zhou, F. Peng, H. Yu, and J. Yang, "Mechanism study on adsorption of acidified multiwalled carbon nanotubes to $\mathrm{Pb}(\mathrm{II})$," Journal of Colloid and Interface Science, vol. 316, no. 2, pp. 277-283, 2007.

[31] P. L. Cao, D. E. Ellis, and V. P. Dravid, "First-principles study of initial stage of Ni thin-film growth on a $\mathrm{TiO}_{2}$ (110) surface," Journal of Materials Research, vol. 14, no. 9, pp. 3684-3689, 1999.

[32] W. Wu, Q. Fan, J. Xu, Z. Niu, and S. Lu, "Sorption-desorption of $\mathrm{Th}(\mathrm{IV})$ on attapulgite: effects of $\mathrm{pH}$, ionic strength and temperature," Applied Radiation and Isotopes, vol. 65, no. 10, pp. 1108-1114, 2007.

[33] Z. Guo, J. Xu, K. Shi, Y. Tang, W. Wu, and Z. Tao, "Eu(III) adsorption/desorption on Na-bentonite: experimental and modeling studies," Colloids and Surfaces A, vol. 339, no. 1-3, pp. 126-133, 2009.

[34] W. Mingming, X. Hongqin, T. Liqiang, Q. Jun, T. Xingquan, and W. Cuiping, "Uptake properties of Eu(III) on Na-attapulgite as a function of $\mathrm{pH}$, ionic strength and temperature," Journal of Radioanalytical and Nuclear Chemistry, vol. 292, no. 2, pp. 763770, 2012.

[35] Q. Fan, D. Shao, Y. Lu, W. Wu, and X. Wang, "Effect of pH, ionic strength, temperature and humic substances on the sorption of 
$\mathrm{Ni}$ (II) to Na-attapulgite," Chemical Engineering Journal, vol. 150, no. 1, pp. 188-195, 2009.

[36] G. Zhao, H. Zhang, Q. Fan et al., "Sorption of copper(II) onto super-adsorbent of bentonite-polyacrylamide composites," Journal of Hazardous Materials, vol. 173, no. 1-3, pp. 661$668,2010$.

[37] X. Tan, M. Fang, C. Chen, S. Yu, and X. Wang, "Counterion effects of nickel and sodium dodecylbenzene sulfonate adsorption to multiwalled carbon nanotubes in aqueous solution," Carbon, vol. 46, no. 13, pp. 1741-1750, 2008.

[38] D. Lin and B. Xing, "Adsorption of phenolic compounds by carbon nanotubes: role of aromaticity and substitution of hydroxyl groups," Environmental Science and Technology, vol. 42, no. 19, pp. 7254-7259, 2008. 

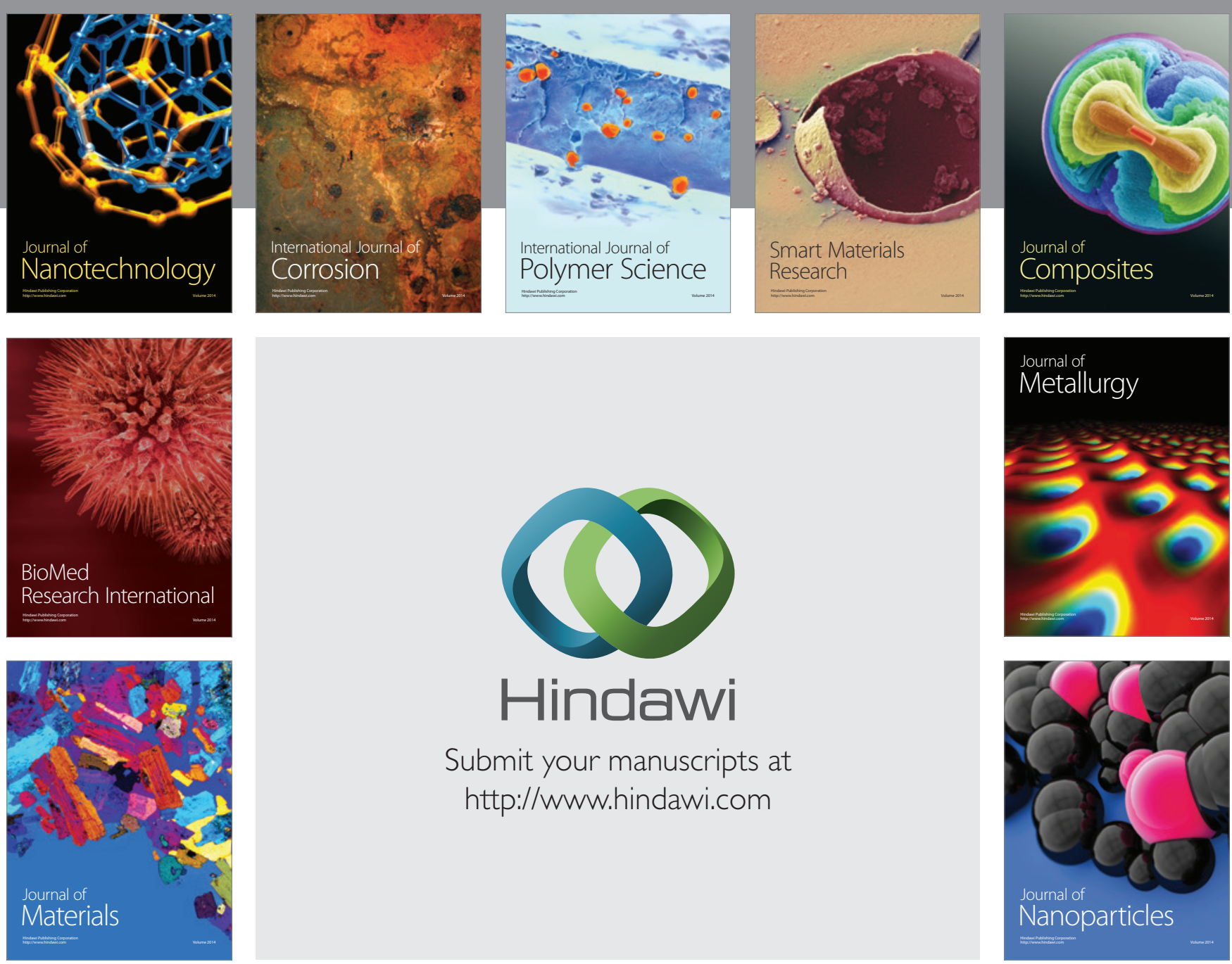

Submit your manuscripts at http://www.hindawi.com
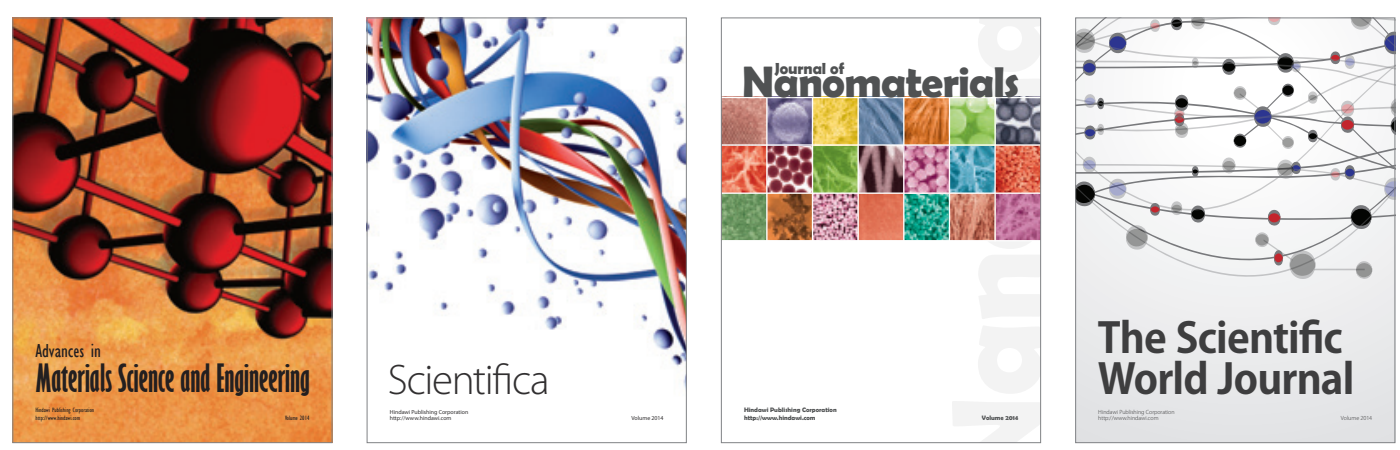

\section{The Scientific World Journal}
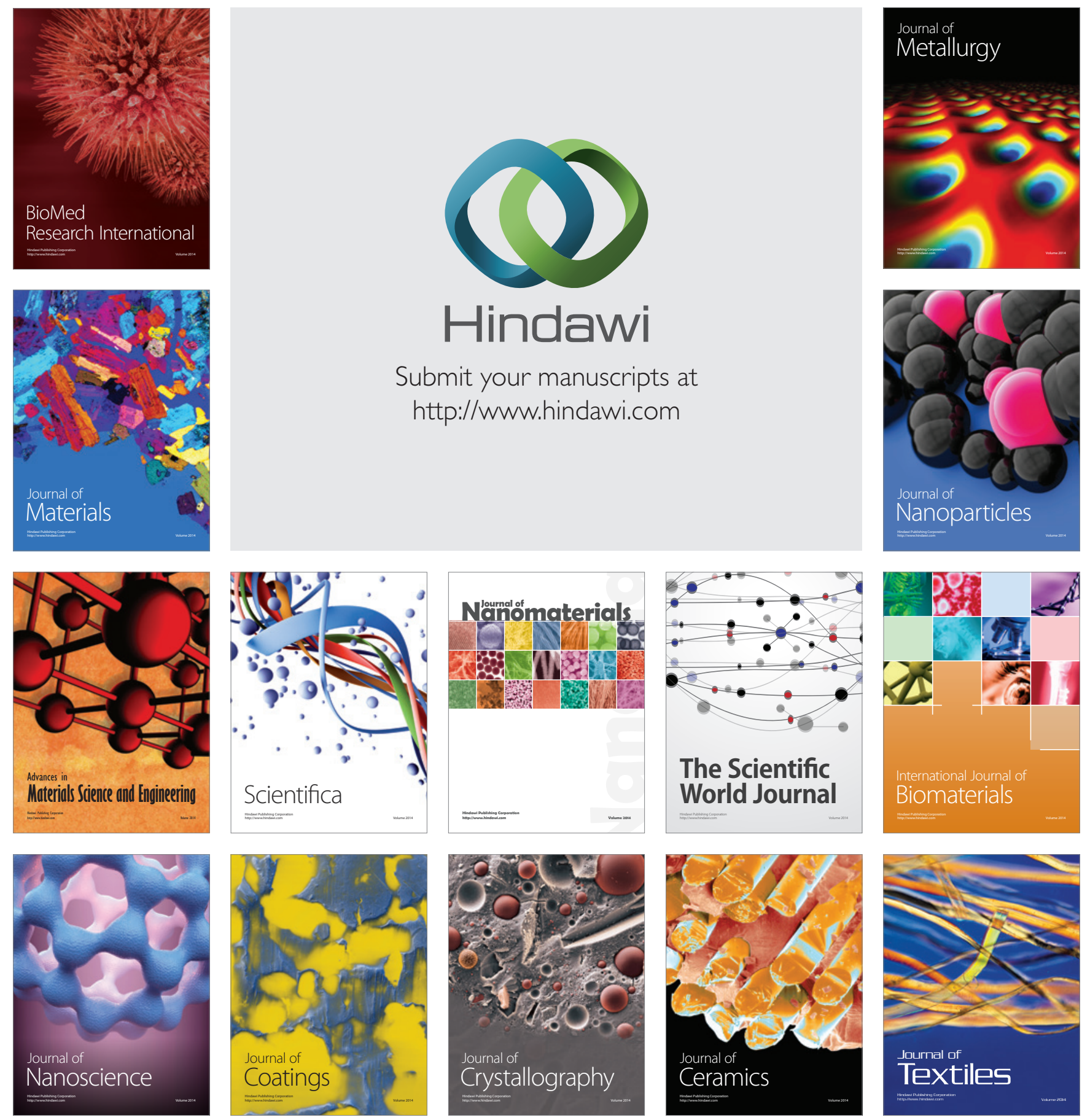